\title{
Expression of programmed cell death ligand 1 (PD-L1) and prevalence of tumor-infiltrating lymphocytes (TILs) in chordoma
}

\author{
Yong Feng ${ }^{1,2}$, Jacson Shen ${ }^{1}$, Yan Gao ${ }^{1}$, Yunfei Liao ${ }^{1,3}$, Gregory Cote ${ }^{4}$, Edwin Choy ${ }^{4}$, \\ Ivan Chebib ${ }^{5}$, Henry Mankin ${ }^{1}$, Francis Hornicek ${ }^{1}$ and Zhenfeng Duan ${ }^{1}$ \\ 1 Sarcoma Biology Laboratory, Department of Orthopaedic Surgery, Massachusetts General Hospital and Harvard Medical \\ School, Jackson, Boston, Massachusetts \\ ${ }^{2}$ Department of Orthopaedic Surgery, Union Hospital, Tongji Medical College, Huazhong University of Science and Technology, \\ Wuhan, China \\ ${ }^{3}$ Department of Endocrine, Union Hospital, Tongji Medical College, Huazhong University of Science and Technology, Wuhan, \\ China \\ ${ }^{4}$ Division of Hematology and Oncology, Massachusetts General Hospital and Harvard Medical School, Boston, Massachusetts, \\ USA \\ ${ }^{5}$ Department of Pathology, Massachusetts General Hospital and Harvard Medical School, Boston, Massachusetts, USA \\ Correspondence to: Zhenfeng Duan, email: zduan@mgh.harvard.edu
}

Keywords: PD-L1, TILS, chordoma, immunotherapy

Received: February 04, $2015 \quad$ Accepted: February 21, $2015 \quad$ Published: March 14, 2015

This is an open-access article distributed under the terms of the Creative Commons Attribution License, which permits unrestricted use, distribution, and reproduction in any medium, provided the original author and source are credited.

\section{ABSTRACT}

Chordomas are primary malignant tumors of the notochord that are resistant to conventional chemotherapy. Expression of programmed cell death ligand 1 (PDL1), prevalence of tumor-infiltrating lymphocytes (TILs), and their clinical relevance in chordoma remain unknown. We evaluated PD-L1 expression in three chordoma cell lines and nine chordoma tissue samples by western blot. Immunohistochemical staining was performed on a chordoma tissue microarray (TMA) that contained 78 tissue specimens. We also correlated the expression of PD-L1 and TILs with clinical outcomes. PD-L1 protein expression was demonstrated to be induced by IFN-Y in both UCH1 and UCH2 cell lines. Across nine human chordoma tissue samples, PD-L1 protein was differentially expressed. $94.9 \%$ of chordoma samples showed positive PD-L1 expression in the TMA. The expression score of PD-L1 for metastatic chordoma tumors was significant higher as compared with non-metastatic chordoma tumors. Expression of PD-L1 protein significantly correlates with the presence of elevated TILs, which correlates with metastasis. In summary, our study showed high levels of PD-L1 are expressed in chordoma, which is correlated with the prevalence of TILs. The current study suggests targeting PD-L1 may be a novel immunotherapeutic strategy for chordoma clinical trials.

\section{INTRODUCTION}

Chordoma, an extremely rare cancer presumably originating from notochord, accounts for $20 \%$ of primary spine tumors and $1-4 \%$ of primary malignant bone tumors $[1,2]$. Epidemiological studies suggest that chordoma affects roughly one in a million individuals; approximately 300 new cases of chordoma are diagnosed in the US per year with an overall median survival of about six years [3]. The standard treatment for these tumors is en-bloc resection accompanied by radiotherapy given both before and after surgery; however, the critical anatomic location (spread along critical bony and neural structures) and the commonly large tumor size make clinical management of these patients difficult. Unlike osteosarcoma, which is relatively sensitive to chemotherapeutic agents, chordoma is resistant to chemotherapy. Distant metastasis occurs in $20-40 \%$ of patients with chordoma of the spine and in less than $10 \%$ of patients with skull-base tumors, with the median survival time after metastasis around one year [35]. Therefore, development of novel therapeutic strategies is critical for this patient population.

There is growing interest in the immunoregulatory receptor programmed cell death 1 (PD-1) and the 
corresponding B7 family of ligands as a pivotal mechanism of tumor immune tolerance and escape in cancer. PD-1 is a member of the B7-CD28 family that co-regulates $\mathrm{T}$-cell receptors and contributes inhibitory signals to mediate physiological immune escape and tolerance $[6,7]$. PD- 1 is expressed in various immune cell types and its activation attenuates T-cell function, survival, and expansion $[8,9]$. Programmed death-ligand 1 (PDL1) is a transmembrane protein that has been shown to be expressed in different tumor cells, and play an important role in suppressing the immune function in diseases like cancer. Expression of PD-L1 by tumor cells is believed to mediate the inhibition of local immune responses, thus shielding the tumor from T-cell mediated killing.

Tumor-infiltrating lymphocytes (TIL) in many cancers express PD-1 and have been shown to be correlated with high PD-L1 expression in different cancers [10-15]. In the inflammatory microenvironment, stimuli such as IFN- $\gamma$ may up regulate PD-L1 expression in peripheral tissues and immune cells to repress the immune response [16-18]. Interestingly, tumors from diverse locations can co-opt this checkpoint system by up regulating PD-L1 expression constitutively or in response to inflammation, including breast, ovarian, gastric, pancreatic, lung, and renal cell carcinomas [1923]. However, PD-L1 expression and prevalence of tumor TILs in chordoma are unknown.

The aim of our study is to investigate the expression level of PD-L1, TILs, and clinicopathological parameters in chordoma, with a particular focus on any potential correlation with prognosis.

\section{RESULTS}

\section{Expression of PD-L1 in chordoma cell lines}

Morphology of chordoma cells usually consist of small non-vacuolated cells, intermediate cells with a wide range of vacuolization, and large heavily vacuolated (physaliferous) cells [24, 25]. UCH1, UCH2, and CH22 cells exhibited characteristics of round nuclei with clear vacuolated cytoplasm (Figure1 A). The expressions of PDL1 were analyzed by western blot in chordoma cell lines. PD-L1 was constitutively expressed in $\mathrm{UCH} 1, \mathrm{UCH} 2$, and
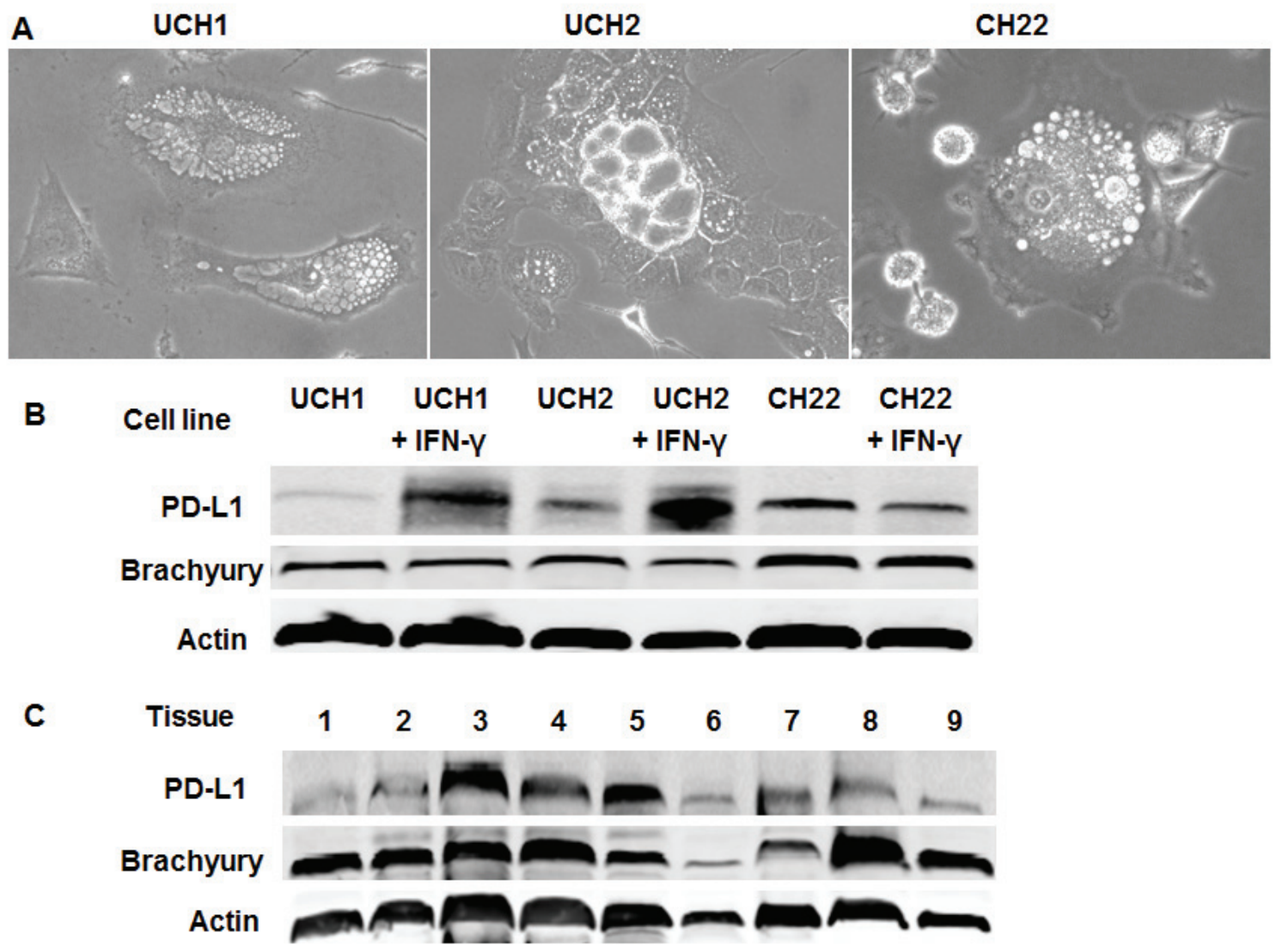

Figure 1: PD-L1 expression in chordoma. (A) Cell morphology and growth characteristics of chordoma cell lines. UCH1, UCH2, and $\mathrm{CH} 22$ cells exhibited round nuclei with clear vacuolated cytoplasm. (B) PD-L1 expression in chordoma cell lines. PD-L1 protein expressions were induced 16-fold and 4-fold by IFN- $\gamma$ in UCH1 and UCH2 cell lines, respectively. (C) PD-L1 expression in chordoma tissues. Relative expressions of PD-L1 were present in 9 chordoma specimens. PD-L1 expression was evaluated from total protein by western blot and absolute expression of PD-L1 was normalized to $\beta$-actin. Three of nine samples were found to have high expression. 
CH22 cells (Figure $1 \mathrm{~B}$ ). PD-L1 protein expressions were induced 16-fold and 4-fold by IFN- $\gamma$ in UCH1 and UCH2 cell lines, respectively, while there was no significant response to IFN- $\gamma$ in the $\mathrm{CH} 22$ cell line. Brachyury protein expression remained at nearly the same level compared with the $\beta$-actin expression in all chordoma cell lines.

\section{PD-L1 expression in chordoma tumor tissue}

To validate the chordoma cell line data, the PD-L1 western blot assay was performed on total protein isolated from 9 chordoma human tumor samples (Figure $1 \mathrm{C}$ ). Brachyury protein expression was present in all tumor samples. PD-L1 protein was also expressed in these samples. Absolute expression of PD-L1 was normalized to $\beta$-actin. Three of nine samples exhibited high expression. There were two samples with intermediate expression, and four samples with low expression.

\section{Correlation between PD-L1 expression and clinicopathology}

PD-L1 immunoreactivity was found in the cytoplasm of tumor cells. PD-L1 staining was detected in 78 TMA samples (including recurrence or metastasis) from 56 patients. The median age was 62 years (range: $24-85)$, and predominantly male $(69.6 \%$ of patients). Of the 78 chordoma samples, $94.9 \%$ were positive for PD-L1 expression. Based on PD-L1 staining intensities in tumor samples, no staining (0) and weak staining (1+) specimens were classified as PD-L1-low patients (57.1\%); moderate staining $(2+)$ and intense staining (3+) specimens were classified as PD-L1-high patients (42.9\%) (Figure $2 \mathrm{~A}$ ). We evaluated the clinicopathologic features of the human tumor samples and found no significant relationship between PD-L1 expression and age at surgery, gender, or tumor location. There was no statistical significance between the median PD-L1 expression score for the relapsed status (1.463) compared with the score for primary tumor (1.345); however, the median PD-L1

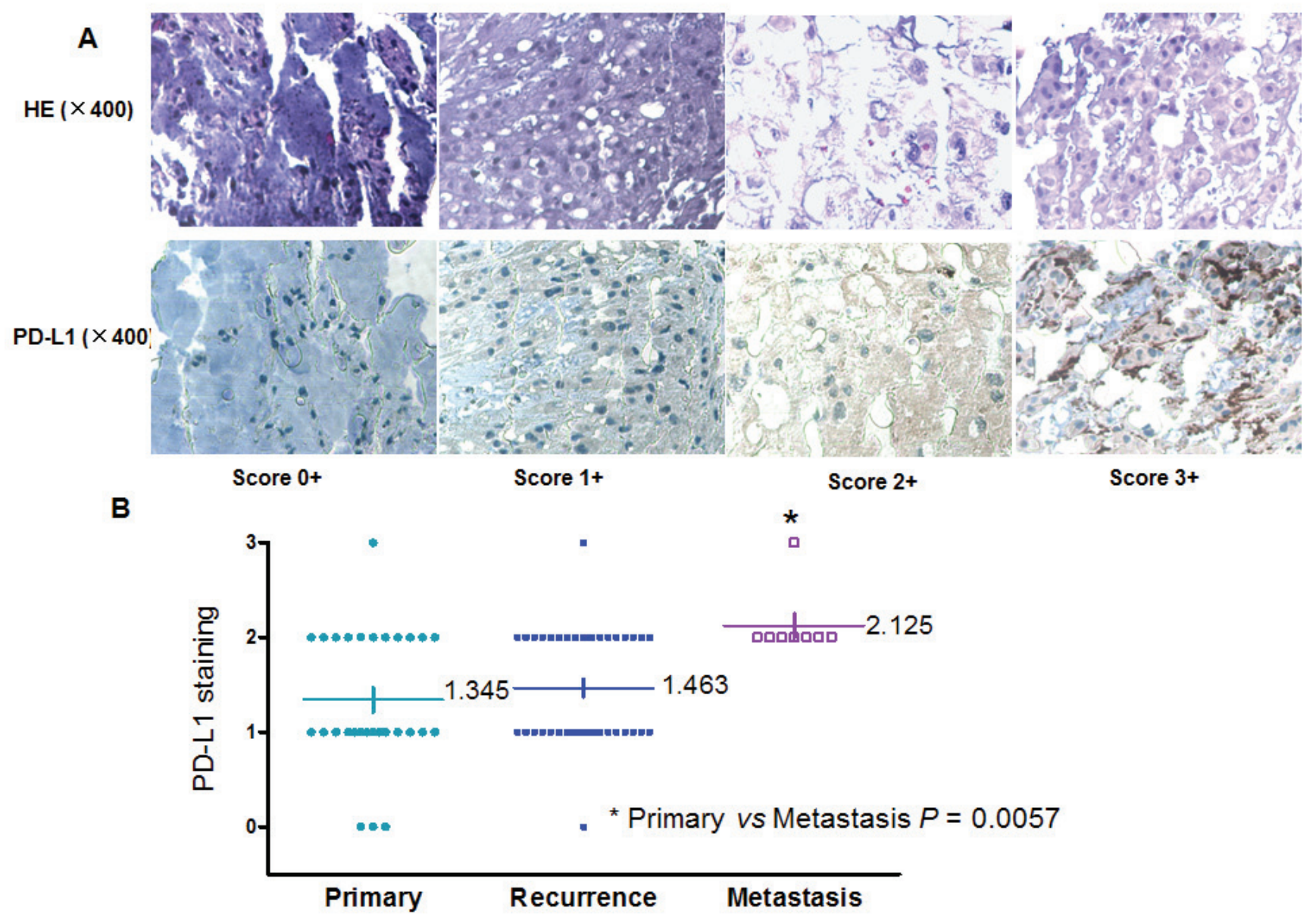

Figure 2: Association of PD-L1 expression with clinical outcome in chordoma. (A) Representative images of different IHC staining intensities of PD-L1 and HE staining were shown in the chordoma TMA. (B) Distribution of PD-L1 staining scores among primary, recurrent, and metastatic tumor tissues. The median PD-L1 expression score for metastatic status (2.215) was significantly higher compared with primary status $(P=0.0057)$. 
expression score for the metastatic group (2.215) was significantly higher compared with the primary group $(P$ $=0.0057$; Figure $2 \mathrm{~B}$ ).

\section{Prognostic value of PD-L1 expression}

The median overall survival for patients with low PD-L1 expressing tumors was 145 months compared with 81 months for patients with high PD-L1 expressing tumors, exhibiting a borderline trend, but not achieving statistical significance $(P=0.0532$; Figure $3 \mathrm{~A})$. We further analyzed the correlation between expression of PD-L1 and the prognosis of chordoma patients. The average expression levels of PD-L1 for survivors and non-survivors were $1.250+$ to $1.625+$, respectively (Figure 3B), and a statistically significant difference in expression PD-L1 expression was identified between these groups of patients $(P=0.0325)$.

\section{Associations between expression of PD-L1 and TILs}

Representative pictures of chordoma cases showing different levels of TILs (scores $0-2+$ ) were depicted in Figure 4A. Accordingly, representative pictures of PDL1 expression were shown in Figure 4B. Based on the scoring criteria of TILs in tumor samples, no TILs were found in $23.1 \%$ cases $(18 / 78)$. The number of cases with rare/few lymphocytic infiltrates (scores $1+$ ) was 37 out of 78 samples $(47.4 \%)$. The percentage of cases with brisk/prominent TILs was $29.5 \%$ (23/78). PD-L1 protein expression was significantly associated with the presence of elevated TILs. Cases with elevated TILs showed significantly higher expression levels of PD-L1 (Figure 4C, $P=0.0088 ; P=0.0006)$.

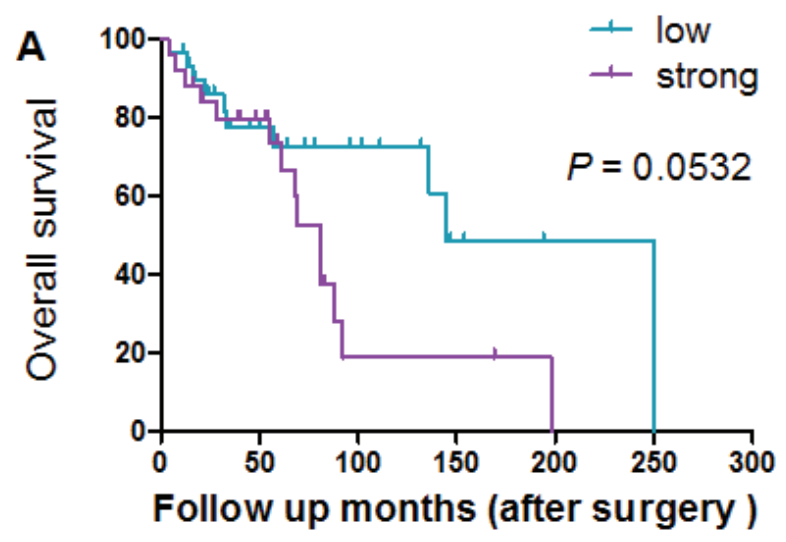

\section{Relationships between TILs clinicopathological features of chordoma}

and

We evaluated the clinicopathologic features of chordoma tumor samples and found no significant relationship between PD-L1 expression and age at surgery, gender, or tumor location. The presence of increased TILs was not significantly associated with survival. The median overall survival for TILs-few patients compared with TILs -prominent patients exhibited a borderline trend, but did not achieve statistical significance (Figure 5A). There was no statistical significance between the median PD-L1 expression score for recurrence status (1.089) compared with the score for primary status $(0.931)$; however, the average TIL expression levels for the primary group and metastasis group were $0.931+$ to $1.500+$, respectively $(P$ $=0.0415$, Figure $5 \mathrm{~B}$ ).

\section{DISCUSSION}

PD-L1 has been shown to be expressed in different solid tumors [19-23]. Our previous study showed that high levels of PD-L1 mRNA are expressed in a subset of osteosarcoma [26]. Many cancer cells contain PDL1 mRNA but do not express PD-L1 protein [27]. We demonstrate that all chordoma cell lines UCH1, UCH2, and $\mathrm{CH} 22$ express PD-L1 protein. Consistent with previous studies that showed the ability of IFN- $\gamma$ to up regulate expression of PD-L1 [28], treatment of UCH1 and $\mathrm{UCH} 2$ cell lines with IFN- $\gamma$ induced significantly higher levels of PD-L1 protein expression. We further confirmed that PD-L1 is expressed at different levels in all 9 chordoma tumor tissue samples. Three of nine samples were found to have a high expression level of PD-L1. These varying expression levels of PD-L1 may result from

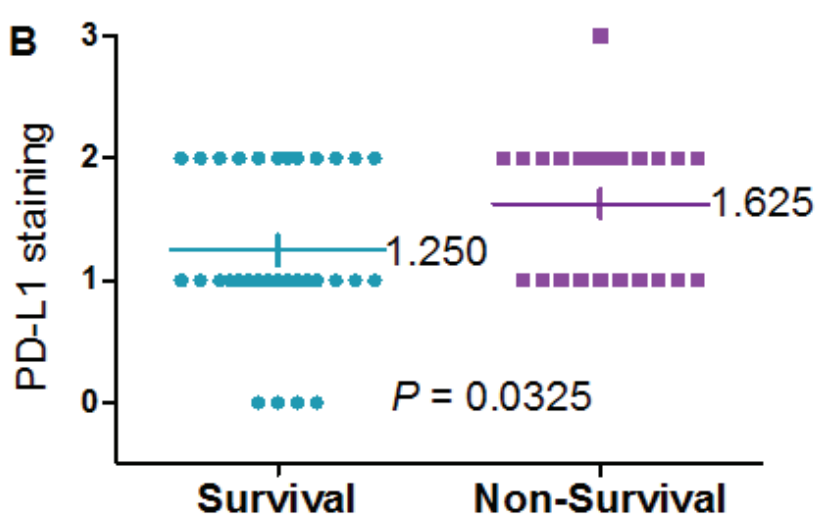

Figure 3: Prognostic value of PD-L1 expression in chordoma. (A) Association between expression of PD-L1 (PD-L1 staining $<2+$ and PD-L1 staining $>2+$ ) and survival in chordoma patients. Kaplan-Meier survival analysis was used to analyze the correlation between the staining of PD-L1 expression and survival. The median overall survival for PD-L1-low patients compared with PD-L1-high patients exhibited a borderline trend, but did not achieve statistical significance. (B) Distribution of PD-L1 expression in survival and non-survival chordoma patient samples as determined by immunohistochemistry. The average PD-L1 expression levels for survivors and non-survivors were $1.250+$ and $1.625+$, respectively $(P=0.0325)$. 


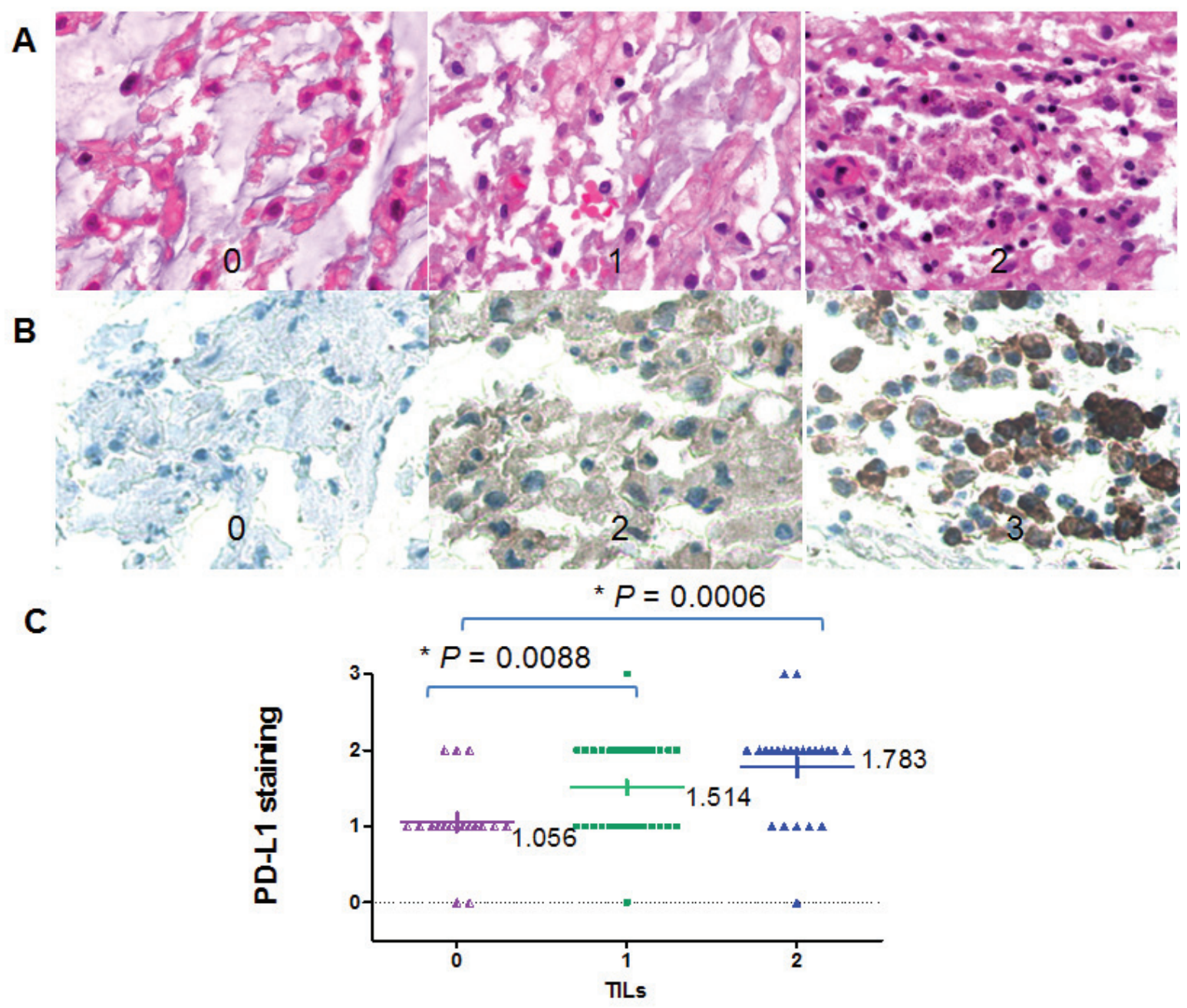

Figure 4: Correlation between PD-L1 expression and TILs by IHC. (A) representative TILs in chordoma tissues (400×); score 0, no TILs; 1, rare/few TILs; 2, brisk/prominent TILs. (B) representative PD-L1expression by IHC in chordoma tissues (400×); (C) A significant positive correlation was shown between PD-L1 protein expression and TILs in patients with chordoma $(P=0.0088 ; P=0.0006)$.
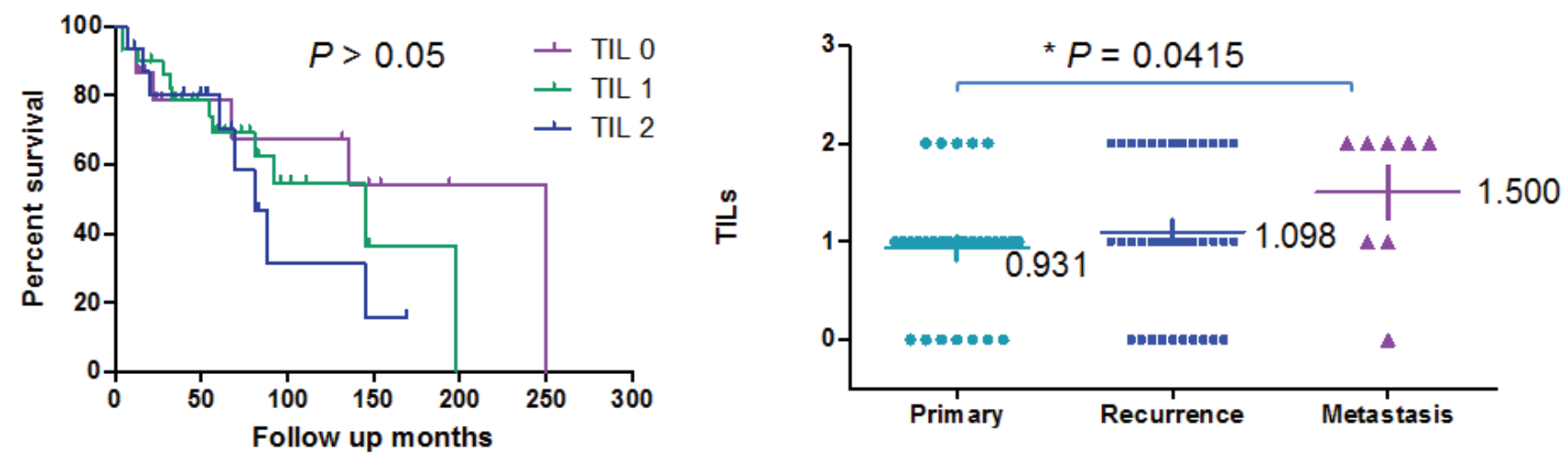

Figure 5: Relationships between clinicopathological features and TILs. (A) Association between expression of TILs (score 0 , no TILs; 1, rare/few TILs; 2, brisk/prominent TILs) and survival in chordoma patients. Kaplan-Meier survival analysis was used to analyze the correlation between the staining of TIL expression and survival. The median overall survival for TILs-low patients compared with TILs-high patients exhibited a borderline trend, but did not achieve statistical significance. (B) Distribution of TIL expression in survival and non-survival chordoma patient samples as determined by immunohistochemistry. The average TILs expression levels for the primary group and the metastasis group were $0.931+$ and $1.500+$, respectively $(P=0.0415)$. 
different chordoma microenvironments.

Loss of tumor suppressor phosphatase and tensin homolog (PTEN) had been shown to increase PDL1 expression and immunoresistance in glioma [29]. In primary glioma tissues, levels of PD-L1 protein correlated with PTEN loss, and tumor-specific T-cells lysed human glioma targets expressing wild-type PTEN more effectively than those expressing mutant PTEN, suggesting that loss of PTEN is associated with high levels of PD-L1 and immune evasion and immunoresistance [2931]. Recently, another study also demonstrated that loss of Lkb1 and PTEN resulted in elevated PD-L1 expression in lung squamous cell carcinoma [32]. Our previous study had found that deficiency of PTEN expression (around $80 \%$ of chordoma tissues) represents a key aspect of chordoma pathogenesis [33]. Interestingly, two of the three chordoma lines (UCH1 and $\mathrm{CH} 22$ ) used in this study that showed high levels of PD-L1 expression also hold genetic changes of PTEN loss [25, 34]. Furthermore, some of these cell lines also harbor other genetic changes, such as loss of p16, SMARCB1, MTAP, or Lkb1, that make them potentially useful models for evaluating PD-L1 targeted immunotherapies [29-31, 35]. These studies suggest PTEN loss may be part of the potential mechanism of increased PD-L1 expression in chordoma. The most direct evidence for this hypothesis has been confirmed in a recent study [36], in which PTEN short hairpin RNA (shRNA) knockdown led to significantly higher cell-surface PDL1 expression and PD-L1 transcripts, suggesting its involvement in transcriptional regulation.

In order to characterize the relationship between the expression level of PD-L1 protein and clinical behavior, we used a chordoma TMA that allowed the simultaneous characterization of the expression status of PD-L1 in 78 chordoma samples. Our study showed that $42.9 \%$ samples were classified as staining highly for PDL1. In our analyses, there was no correlation of PD-L1 expression with age at surgery, gender, or tumor location. Our study showed the median PD-L1 expression score for the group with metastsis was significantly higher compared with the PD-L1 expression score for the group without metastasis. Furthermore, previous studies have demonstrated a strong correlation between the expression of PD-L1 and poor prognosis in different solid tumors, including glioblastoma, pancreas, ovarian, breast, renal cell carcinomas, head and neck squamous cell carcinomas, esophageal, and non-small cell lung cancers [27, 29, 37-41]. The longest length of follow up of chordoma patients in our current study was over 20 years. KaplanMeier survival analysis showed that there was a trend for poorer overall survival for chordoma patients with high expression of PD-L1. The average expression level of PDL1 for non-survival patients was significantly higher than the survival patients group.

TILs induce expression of PD-L1 through up regulation of cytokines, such as IFN- $\gamma$ [42]. In accordance with IFN- $\gamma$ up regulating PD-L1 protein in chordoma cell lines, our chordoma TMA samples with increasing TILs also showed significantly higher PD-L1 expression. This finding was consistent with a recently published study on PD-L1 protein co-localizing with TILs [28]. We further analyzed the association between TILs and clinicopathological features. However, no significant difference between the median overall survival for TILszero patients with TILs-prominent or TILs-few patients was found. The average TIL expression level for the metastasis group was significantly higher than the primary group. Consistent with these findings, TIL infiltration could facilitate metastases in melanoma [14].

Multiple agents targeting the PD-1/PD-L1 system in cancer are currently at different stages of clinical development [43-46]. These promising clinical trials show that blockade of the PD-1/PD-L1 axis using monoclonal antibodies can reactivate the antitumor immune response and induce lasting clinical benefit in nearly one third of (heavily pretreated) patients with advanced melanoma, lung, and renal cell carcinomas $[44,46]$. In these previously heavily treated patients, the response rates ranged from $18 \%$ to $28 \%$, depending on the tumor histology, and importantly the responses were durable. Notably, tumor PD-L1 positivity scores determined by immunohistochemistry (IHC) were found to be predictive of response to the anti-PD-compound [44]. Most importantly, anti-PD-L1 treatment and irradiation synergistically promote anti-tumor immunity in mice [47], and acquired resistance to fractionated radiotherapy can be overcome by concurrent PD-L1 blockade.

Since these initial reports of clinical activity of PDL1 blockade therapy in several tumor types, including advanced melanoma, lung, and renal cell carcinomas in 2012, there has been a growing interest in immunotherapy to see if these agents could be applied to other tumor subtypes. Furthermore, PD-L1 silencing with siRNA has been shown to inhibit colon cancer proliferation, migration, and invasion in vitro [48]. Increased PD-L1 expression in triple-negative breast cancer cells induced by PTEN shRNA loss led to decreased T-cell proliferation and increased apoptosis [36]. On the other hand, inhibition of PD-L1 also showed enhance NK and CD8(+) T cellmediated immune function [49]. In conclusion, the present study shows that PD-L1 is highly expressed in chordoma. Expression of PD-L1 is also correlated with the prevalence of TILs in chordoma. This study suggests the potential of using PD-L1 based immunotherapy for the treatment of chordoma. 
Table 1: The clinical parameters of chordoma tissue microarray

\begin{tabular}{|c|c|c|}
\hline parameters & & $\mathbf{n}$ \\
\hline Age & & 56 \\
\hline & $<45$ & 7 \\
\hline & $45-60$ & 16 \\
\hline & $>60$ & 30 \\
\hline & N/A & 3 \\
\hline Gender & & 56 \\
\hline & Male & 39 \\
\hline & Female & 14 \\
\hline & N/A & 3 \\
\hline Location & & 56 \\
\hline & Mobilespine & 21 \\
\hline & Sacum & 35 \\
\hline & & 78 \\
\hline & Primary & 29 \\
\hline & Metastasis & 8 \\
\hline & Local relapse & 41 \\
\hline & & 56 \\
\hline & NED & 24 \\
\hline & AWD & 3 \\
\hline & DOD & 22 \\
\hline & DOO & 7 \\
\hline & & $15 \%$ \\
\hline
\end{tabular}

N/A:not applicable, NED: no evidence of disease, AWD: alive with disease, DOD: dead of disease, DOO: dead of others disease.

\section{MATERIALS AND METHODS}

\section{Cell lines and cell culture}

UCH1 and UCH2 are established human chordoma cell lines and were kindly provided by Dr. Silke Bruderlein (University Hospitals of Ulm, Germany) [34, 50]. Another human chordoma cell line, $\mathrm{CH} 22$, was established in our laboratory as previous reported [25]. These cell lines were cultured in the DMEM (Invitrogen, Carlsbad, CA) medium, supplemented with $10 \%$ fetal bovine serum (FBS) and 1\% penicillin/streptomycin (Invitrogen). Cells were cultured in a humidified incubator with a $5 \% \mathrm{CO}^{2}$ $95 \%$ air atmosphere at $37^{\circ} \mathrm{C}$ and passaged every $3-4$ days using trypsin-EDTA when cell confluence reached 90-100\%.

Cells were treated with recombinant human interferon IFN- $\gamma$ (Pierce Biotechnology, Rockford, IL), as previously described [51]. Briefly, $3 \times 10^{5}$ cells were incubated at $37^{\circ} \mathrm{C}$ for 48 hours in medium supplemented with $100 \mathrm{U} / \mathrm{mL}$, and then washed with excess culture medium.

\section{Western blot assay}

Expression of PD-L1 protein was evaluated by Western Blot analysis. Protein lysates from chordoma cell lines were extracted using $1 \times$ Cell Lysis Buffer (Cell Signaling Technology, MA). The protein concentrations were determined using Protein Assay Reagents (Bio-Rad, CA) and a SPECTRAmax Microplate Spectrophotometer from Molecular Devices (Sunnyvale, CA). The primary antibodies for PD-L1 (1:1000 dilution), brachyury (1:1000 dilution), and $\beta$-actin (1:2,000 dilution) were purchased from Abcam, Santa Cruz, and Sigma-Aldrich, respectively. The secondary antibodies were bound to IRDye1 $800 \mathrm{CW}$ or IRDye1 680LT (LI-COR Biosciences, NE). Western blots were carried out as previously described [52]. Normalization was performed using actin as an endogenous control. Membrane signals were scanned using an Odyssey infrared imaging system and analyzed using Odyssey 3.0 software (LI-COR Biosciences, NE). The protein levels were quantified with NIH Image $\mathrm{J}$ software.

\section{Human chordoma tumor tissues}

Nine of the chordoma tissue samples (Tissue1Tissue9) were obtained from the Massachusetts General Hospital Sarcoma Tissue Bank and were used in 
Table2: Clinical data of protein samples from chordoma tissues

\begin{tabular}{|c|c|c|c|c|c|c|}
\hline Sample & Age & Sex & Histologic Subtype & Metastatic & Recurrent & Location \\
\hline 1 & 48 & $\mathrm{M}$ & Conventional & no & no & Sacrum \\
\hline 2 & 46 & $\mathrm{M}$ & Conventional & no & no & Sacrum \\
\hline 3 & 74 & $\mathrm{M}$ & Conventional & no & yes & Sacrum \\
\hline 4 & 60 & $\mathrm{~F}$ & Conventional & no & no & Sacrum \\
\hline 5 & 35 & $\mathrm{M}$ & Conventional & yes & no & Cervical \\
\hline 6 & 71 & $\mathrm{~F}$ & Conventional & no & no & Sacrum \\
\hline 7 & 52 & $\mathrm{~F}$ & Conventional & no & yes & Sacrum \\
\hline 8 & 74 & $\mathrm{M}$ & Conventional & no & yes & Lumbar \\
\hline 9 & 52 & $\mathrm{M}$ & Conventional & no & &
\end{tabular}

accordance with the policies of the institutional review board of the hospital (IRB protocol \# 2007P-002464). Written informed consent was obtained from all patients whose specimens and clinical information were used for this research study. All tissue diagnoses were confirmed histologically, and proteins were extracted from these frozen tissues. The data of each patient's age, gender, metastasis, recurrence, tumor location(s), follow up months, and disease status were collected (Table 1). The expression of PD-L1 in these 9 chordoma samples was determined by Western blot assay.

\section{Chordoma Tissue Microarray (TMA) and immunohistochemistry}

Pathologically confirmed chordoma tissues were obtained from patients who had undergone surgical resection in our hospital, and were conducted according to the policies of the institutional review board of the hospital (IRB protocol \# 2007P-002464). A retrospective study of 78 samples (including recurrent and metastatic) from 56 chordoma patients was identified for the tissue microarray (TMA) immunohistochemical staining as previously reported [53]. The clinical data of each patient's age, gender, tumor location(s), and disease status of chordoma patients were presented in the Table 2 (supplement data).

The expression level of PD-L1 was determined based on the Immunohistochemistry Protocol (Paraffin) from Cell Signaling Technology (Beverly, MA). Briefly, 5 - $\mu$ m-thick array sections were baked at $60^{\circ} \mathrm{C}$ for $1 \mathrm{~h}$, dewaxed with xylene (three times for 5 minutes each), transferred through $100 \%$ ethanol (twice for 5 minutes each), rehydrated through graded alcohol, and then immersed in deionized water for 10 minutes. Antigen retrieval was processed with Target Retrieval Solution (Dako, North America, Inc., CA). After antigen retrieval, the slide was washed with PBS twice for 5 minutes. Following the process of antigen retrieval, endogenous peroxidase activity was quenched by incubation in 3\% hydrogen peroxide. After protein blocking with blocking solution (Cell Signaling Technology) for 1 hour at room temperature, primary antibody (1:50 dilution, in $1 \%$ bovine serum albumin PBS) was applied at $4^{\circ} \mathrm{C}$ overnight in a humidified chamber. Primary PD-L1 antibody was probed at $4{ }^{\circ} \mathrm{C}$ overnight. Each step was succeeded by three Tris-buffered saline (TBS) rinses, and the bound antibody on the array was detected by using SignalStain $\mathbb{}($ Boost Detection Reagent (Cell Signaling Technology) and SignalStain ${ }^{\circledR}$ DAB (Cell Signaling Technology). Finally, sections were counterstained with Hematoxylin QS (VectorLaboratories) and the slide was mounted with VectaMount AQ (Vector Laboratories) for long-term preservation. The immunostaining intensity pattern of PDL1 was assessed on a scale semi-quantitatively as follows: 0 , no staining; $1+$, weak staining; $2+$, moderate staining; and $3+$, intense staining. Scoring was calculated from the mean of the two independently conducted assessments. PD-L1 staining images were obtained by using a Nikon Eclipse Ti-U fluorescence microscope (Nikon Corp) with a SPOT RT digital camera (Diagnostic Instruments Inc.).

\section{Evaluation of tumor-infiltrating lymphocytes}

The TIL analysis were performed on the hematoxylin and eosin-stained chordoma TMA slide. Scores of the TMA were evaluated for the presence of TILs at $200 \times$ magnification and semi-quantitatively as follows: score 0 , no TILs; 1, rare/few TILs; 2, brisk/ prominent TILs.

\section{Statistical analyses}

All statistical analyses were performed using GraphPad Prism software 5.0. Kaplan-Meier survival curves were generated to examine the relationship between the expression levels of PD-L1 and patients' survival rate. Survival time was calculated from the date of tumor diagnosis to the date of death or last followup. The statistical significance between two groups was determined using unpaired Student's t-test. Data were expressed as mean \pm standard error of the mean (SEM). For comparison between expression of PD-L1 and immune infiltrates, a one-way ANOVA analysis was used. The statistical significance is described in figures and in legends. $P$ values $<0.05$ were considered as statistically 
significant.

\section{ACKNOWLEDGEMENTS}

This work was supported in part by grants from the Stephan L. Harris Fund, the Gattegno and Wechsler funds, by the Jennifer Hunter Yates Foundation. Support has also been provided by the Chordoma Foundation. Dr. Duan is supported, in part, through a grant from Sarcoma Foundation of America (SFA), a grant from National Cancer Institute (NCI)/National Institutes of Health (NIH), UO1, CA151452-01, a grant from Sarcoma SPORE/NIH, and a grant from an Academic Enrichment Fund of MGH Orthopedic Surgery. Dr. Feng is supported by the National Natural Science Foundation of China (NSFC), 81101375.

\section{CONFLICT OF INTEREST STATEMENT}

No potential conflicts of interest were disclosed by the authors.

\section{REFERENCES}

1. Mindell ER. Chordoma. The Journal of bone and joint surgery American volume. 1981; 63(3):501-505.

2. Chugh R, Tawbi H, Lucas DR, Biermann JS, Schuetze SM and Baker LH. Chordoma: the nonsarcoma primary bone tumor. The oncologist. 2007; 12(11):1344-1350.

3. McMaster ML, Goldstein AM, Bromley CM, Ishibe $\mathrm{N}$ and Parry DM. Chordoma: incidence and survival patterns in the United States, 1973-1995. Cancer causes \& control : CCC. 2001; 12(1):1-11.

4. Baratti D, Gronchi A, Pennacchioli E, Lozza L, Colecchia M, Fiore M and Santinami M. Chordoma: natural history and results in 28 patients treated at a single institution. Annals of surgical oncology. 2003; 10(3):291-296.

5. O'Neill P, Bell BA, Miller JD, Jacobson I and Guthrie W. Fifty years of experience with chordomas in southeast Scotland. Neurosurgery. 1985; 16(2):166-170.

6. Nurieva RI, Liu X and Dong C. Yin-Yang of costimulation: crucial controls of immune tolerance and function. Immunological reviews. 2009; 229(1):88-100.

7. Schreiber RD, Old LJ and Smyth MJ. Cancer immunoediting: integrating immunity's roles in cancer suppression and promotion. Science (New York, NY). 2011; 331(6024):1565-1570.

8. Blank C and Mackensen A. Contribution of the PD-L1/PD-1 pathway to T-cell exhaustion: an update on implications for chronic infections and tumor evasion. Cancer immunology, immunotherapy : CII. 2007; 56(5):739-745.

9. Keir ME, Butte MJ, Freeman GJ and Sharpe AH. PD-1 and its ligands in tolerance and immunity. Annual review of immunology. 2008; 26:677-704.

10. Cho YA, Yoon HJ, Lee JI, Hong SP and Hong SD.
Relationship between the expressions of PD-L1 and tumorinfiltrating lymphocytes in oral squamous cell carcinoma. Oral oncology. 2011; 47(12):1148-1153.

11. Muenst S, Soysal SD, Gao F, Obermann EC, Oertli D and Gillanders WE. The presence of programmed death 1 (PD1)-positive tumor-infiltrating lymphocytes is associated with poor prognosis in human breast cancer. Breast cancer research and treatment. 2013; 139(3):667-676.

12. Berghoff AS, Kiesel B, Widhalm G, Rajky O, Ricken G, Wohrer A, Dieckmann K, Filipits M, Brandstetter A, Weller M, Kurscheid S, Hegi ME, Zielinski CC, Marosi C, Hainfellner JA, Preusser M, et al. Programmed death ligand 1 expression and tumor-infiltrating lymphocytes in glioblastoma. Neuro-oncology. 2014.

13. D'Angelo SP, Shoushtari AN, Agaram NP, Kuk D, Qin LX, Carvajal RD, Dickson MA, Gounder M, Keohan ML, Schwartz GK and Tap WD. Prevalence of tumor-infiltrating lymphocytes and PD-L1 expression in the soft tissue sarcoma microenvironment. Human pathology. 2014.

14. Berghoff AS, Ricken G, Widhalm G, Rajky O, Dieckmann K, Birner P, Bartsch R, Holler C and Preusser M. Tumourinfiltrating lymphocytes and expression of programmed death ligand 1 (PD-L1) in melanoma brain metastases. Histopathology. 2015; 66(2):289-299.

15. Kakavand H, Wilmott JS, Menzies AM, Vilain R, Haydu LE, Yearley JH, Thompson JF, Kefford RF, Hersey P, Long GV and Scolyer RA. PD-L1 expression and tumorinfiltrating lymphocytes define different subsets of MAPK inhibitor treated melanoma patients. Clinical cancer research : an official journal of the American Association for Cancer Research. 2015.

16. Taube JM, Anders RA, Young GD, Xu H, Sharma R, McMiller TL, Chen S, Klein AP, Pardoll DM, Topalian SL and Chen L. Colocalization of inflammatory response with B7-h1 expression in human melanocytic lesions supports an adaptive resistance mechanism of immune escape. Science translational medicine. 2012; 4(127):127ra137.

17. Dong H, Strome SE, Salomao DR, Tamura H, Hirano F, Flies DB, Roche PC, Lu J, Zhu G, Tamada K, Lennon VA, Celis E and Chen L. Tumor-associated B7-H1 promotes T-cell apoptosis: a potential mechanism of immune evasion. Nature medicine. 2002; 8(8):793-800.

18. Zou W and Chen L. Inhibitory B7-family molecules in the tumour microenvironment. Nature reviews Immunology. 2008; 8(6):467-477.

19. Thompson RH, Kuntz SM, Leibovich BC, Dong H, Lohse CM, Webster WS, Sengupta S, Frank I, Parker AS, Zincke H, Blute ML, Sebo TJ, Cheville JC and Kwon ED. Tumor B7-H1 is associated with poor prognosis in renal cell carcinoma patients with long-term follow-up. Cancer research. 2006; 66(7):3381-3385.

20. Nomi T, Sho M, Akahori T, Hamada K, Kubo A, Kanehiro H, Nakamura S, Enomoto K, Yagita H, Azuma M and Nakajima Y. Clinical significance and therapeutic potential of the programmed death-1 ligand/programmed death-1 
pathway in human pancreatic cancer. Clinical cancer research : an official journal of the American Association for Cancer Research. 2007; 13(7):2151-2157.

21. Wu C, Zhu Y, Jiang J, Zhao J, Zhang XG and Xu N. Immunohistochemical localization of programmed death-1 ligand-1 (PD-L1) in gastric carcinoma and its clinical significance. Acta histochemica. 2006; 108(1):19-24.

22. Carpenito C, Milone MC, Hassan R, Simonet JC, Lakhal M, Suhoski MM, Varela-Rohena A, Haines KM, Heitjan DF, Albelda SM, Carroll RG, Riley JL, Pastan I and June $\mathrm{CH}$. Control of large, established tumor xenografts with genetically retargeted human T cells containing CD28 and CD137 domains. Proceedings of the National Academy of Sciences of the United States of America. 2009; 106(9):3360-3365.

23. Ghebeh H, Mohammed S, Al-Omair A, Qattan A, Lehe C, Al-Qudaihi G, Elkum N, Alshabanah M, Bin Amer S, Tulbah A, Ajarim D, Al-Tweigeri T and Dermime S. The B7-H1 (PD-L1) T lymphocyte-inhibitory molecule is expressed in breast cancer patients with infiltrating ductal carcinoma: correlation with important high-risk prognostic factors. Neoplasia (New York, NY). 2006; 8(3):190-198.

24. Yang C, Hornicek FJ, Wood KB, Schwab JH, Choy E, Iafrate J, Rosenberg A, Nielsen GP, Xavier RJ, Mankin $\mathrm{H}$ and Duan Z. Characterization and analysis of human chordoma cell lines. Spine. 2010; 35(13):1257-1264.

25. Liu X, Nielsen GP, Rosenberg AE, Waterman PR, Yang W, Choy E, Sassi S, Yang S, Harmon DC, Yang C, Schwab JH, Kobayashi E, Mankin HJ, Xavier R, Weissleder R, Duan Z, et al. Establishment and characterization of a novel chordoma cell line: $\mathrm{CH} 22$. Journal of orthopaedic research : official publication of the Orthopaedic Research Society. 2012; 30(10):1666-1673.

26. Shen JK, Cote GM, Choy E, Yang P, Harmon D, Schwab J, Nielsen GP, Chebib I, Ferrone S, Wang X, Wang Y, Mankin H, Hornicek FJ and Duan Z. Programmed cell death ligand 1 expression in osteosarcoma. Cancer immunology research. 2014; 2(7):690-698.

27. Yamazaki T, Akiba H, Iwai H, Matsuda H, Aoki M, Tanno Y, Shin T, Tsuchiya H, Pardoll DM, Okumura K, Azuma $\mathrm{M}$ and Yagita $\mathrm{H}$. Expression of programmed death 1 ligands by murine T cells and APC. Journal of immunology (Baltimore, Md : 1950). 2002; 169(10):5538-5545.

28. Mathios D, Ruzevick J, Jackson CM, Xu H, Shah S, Taube JM, Burger PC, McCarthy EF, Quinones-Hinojosa A, Pardoll DM and Lim M. PD-1, PD-L1, PD-L2 expression in the chordoma microenvironment. Journal of neurooncology. 2015; 121(2):251-259.

29. Parsa AT, Waldron JS, Panner A, Crane CA, Parney IF, Barry JJ, Cachola KE, Murray JC, Tihan T, Jensen MC, Mischel PS, Stokoe D and Pieper RO. Loss of tumor suppressor PTEN function increases B7-H1 expression and immunoresistance in glioma. Nature medicine. 2007; 13(1):84-88.

30. Han SJ, Ahn BJ, Waldron JS, Yang I, Fang S, Crane CA,
Pieper RO and Parsa AT. Gamma interferon-mediated superinduction of B7-H1 in PTEN-deficient glioblastoma: a paradoxical mechanism of immune evasion. Neuroreport. 2009; 20(18):1597-1602.

31. Okada H, Kohanbash G, Zhu X, Kastenhuber ER, Hoji A, Ueda R and Fujita M. Immunotherapeutic approaches for glioma. Critical reviews in immunology. 2009; 29(1):1-42.

32. Xu C, Fillmore CM, Koyama S, Wu H, Zhao Y, Chen Z, Herter-Sprie GS, Akbay EA, Tchaicha JH, Altabef A, Reibel JB, Walton Z, Ji H, Watanabe H, Janne PA, Castrillon DH, et al. Loss of Lkb1 and Pten leads to lung squamous cell carcinoma with elevated PD-L1 expression. Cancer cell. 2014; 25(5):590-604.

33. Le LP, Nielsen GP, Rosenberg AE, Thomas D, Batten JM, Deshpande V, Schwab J, Duan Z, Xavier RJ, Hornicek FJ and Iafrate AJ. Recurrent chromosomal copy number alterations in sporadic chordomas. PloS one. 2011; 6(5):e18846.

34. Bruderlein S, Sommer JB, Meltzer PS, Li S, Osada T, Ng D, Moller P, Alcorta DA and Kelley MJ. Molecular characterization of putative chordoma cell lines. Sarcoma. 2010; 2010:630129.

35. Choy E, MacConaill LE, Cote GM, Le LP, Shen JK, Nielsen GP, Iafrate AJ, Garraway LA, Hornicek FJ and Duan Z. Genotyping cancer-associated genes in chordoma identifies mutations in oncogenes and areas of chromosomal loss involving CDKN2A, PTEN, and SMARCB1. PloS one. 2014; 9(7):e101283.

36. Mittendorf EA, Philips AV, Meric-Bernstam F, Qiao N, Wu Y, Harrington S, Su X, Wang Y, Gonzalez-Angulo AM, Akcakanat A, Chawla A, Curran M, Hwu P, Sharma P, Litton JK, Molldrem JJ, et al. PD-L1 expression in triplenegative breast cancer. Cancer immunology research. 2014; 2(4):361-370.

37. Hamanishi J, Mandai M, Iwasaki M, Okazaki T, Tanaka Y, Yamaguchi K, Higuchi T, Yagi H, Takakura K, Minato N, Honjo T and Fujii S. Programmed cell death 1 ligand 1 and tumor-infiltrating CD8+ T lymphocytes are prognostic factors of human ovarian cancer. Proceedings of the National Academy of Sciences of the United States of America. 2007; 104(9):3360-3365.

38. Thompson RH, Gillett MD, Cheville JC, Lohse CM, Dong H, Webster WS, Krejci KG, Lobo JR, Sengupta S, Chen L, Zincke H, Blute ML, Strome SE, Leibovich BC and Kwon ED. Costimulatory B7-H1 in renal cell carcinoma patients: Indicator of tumor aggressiveness and potential therapeutic target. Proceedings of the National Academy of Sciences of the United States of America. 2004; 101(49):17174-17179.

39. Strome SE, Dong H, Tamura H, Voss SG, Flies DB, Tamada K, Salomao D, Cheville J, Hirano F, Lin W, Kasperbauer JL, Ballman KV and Chen L. B7-H1 blockade augments adoptive T-cell immunotherapy for squamous cell carcinoma. Cancer research. 2003; 63(19):6501-6505.

40. Ohigashi Y, Sho M, Yamada Y, Tsurui Y, Hamada K, Ikeda N, Mizuno T, Yoriki R, Kashizuka H, Yane K, 
Tsushima F, Otsuki N, Yagita H, Azuma M and Nakajima Y. Clinical significance of programmed death-1 ligand-1 and programmed death-1 ligand-2 expression in human esophageal cancer. Clinical cancer research : an official journal of the American Association for Cancer Research. 2005; 11(8):2947-2953.

41. Konishi J, Yamazaki K, Azuma M, Kinoshita I, DosakaAkita $\mathrm{H}$ and Nishimura M. B7-H1 expression on non-small cell lung cancer cells and its relationship with tumorinfiltrating lymphocytes and their PD-1 expression. Clinical cancer research : an official journal of the American Association for Cancer Research. 2004; 10(15):5094-5100.

42. Taube JM, Klein A, Brahmer JR, Xu H, Pan X, Kim JH, Chen L, Pardoll DM, Topalian SL and Anders RA. Association of PD-1, PD-1 ligands, and other features of the tumor immune microenvironment with response to antiPD-1 therapy. Clinical cancer research : an official journal of the American Association for Cancer Research. 2014; 20(19):5064-5074.

43. Hamid O, Robert C, Daud A, Hodi FS, Hwu WJ, Kefford R, Wolchok JD, Hersey P, Joseph RW, Weber JS, Dronca R, Gangadhar TC, Patnaik A, Zarour H, Joshua AM, Gergich $\mathrm{K}$, et al. Safety and tumor responses with lambrolizumab (anti-PD-1) in melanoma. The New England journal of medicine. 2013; 369(2):134-144.

44. Topalian SL, Hodi FS, Brahmer JR, Gettinger SN, Smith DC, McDermott DF, Powderly JD, Carvajal RD, Sosman JA, Atkins MB, Leming PD, Spigel DR, Antonia SJ, Horn L, Drake CG, Pardoll DM, et al. Safety, activity, and immune correlates of anti-PD-1 antibody in cancer. The New England journal of medicine. 2012; 366(26):24432454.

45. Brahmer JR, Drake CG, Wollner I, Powderly JD, Picus J, Sharfman WH, Stankevich E, Pons A, Salay TM, McMiller TL, Gilson MM, Wang C, Selby M, Taube JM, Anders R, Chen L, et al. Phase I study of single-agent anti-programmed death-1 (MDX-1106) in refractory solid tumors: safety, clinical activity, pharmacodynamics, and immunologic correlates. Journal of clinical oncology : official journal of the American Society of Clinical Oncology. 2010; 28(19):3167-3175.

46. Brahmer JR, Tykodi SS, Chow LQ, Hwu WJ, Topalian SL, Hwu P, Drake CG, Camacho LH, Kauh J, Odunsi K, Pitot HC, Hamid O, Bhatia S, Martins R, Eaton K, Chen S, et al. Safety and activity of anti-PD-L1 antibody in patients with advanced cancer. The New England journal of medicine. 2012; 366(26):2455-2465.

47. Deng L, Liang H, Burnette B, Beckett M, Darga T, Weichselbaum RR and Fu YX. Irradiation and anti-PD-L1 treatment synergistically promote antitumor immunity in mice. The Journal of clinical investigation. 2014; 124(2):687-695.

48. Shi SJ, Wang LJ, Wang GD, Guo ZY, Wei M, Meng YL, Yang AG and Wen WH. B7-H1 expression is associated with poor prognosis in colorectal carcinoma and regulates the proliferation and invasion of HCT116 colorectal cancer cells. PloS one. 2013; 8(10):e76012.

49. Dolina JS, Sung SS, Novobrantseva TI, Nguyen TM and Hahn YS. Lipidoid Nanoparticles Containing PD-L1 siRNA Delivered In Vivo Enter Kupffer Cells and Enhance NK and CD8(+) T Cell-mediated Hepatic Antiviral Immunity. Molecular therapy Nucleic acids. 2013; 2:e72.

50. Scheil S, Bruderlein S, Liehr T, Starke H, Herms J, Schulte $\mathrm{M}$ and Moller P. Genome-wide analysis of sixteen chordomas by comparative genomic hybridization and cytogenetics of the first human chordoma cell line, U-CH1. Genes, chromosomes \& cancer. 2001; 32(3):203-211.

51. Haile ST, Bosch JJ, Agu NI, Zeender AM, Somasundaram P, Srivastava MK, Britting S, Wolf JB, Ksander BR and Ostrand-Rosenberg S. Tumor cell programmed death ligand 1-mediated $\mathrm{T}$ cell suppression is overcome by coexpression of CD80. Journal of immunology (Baltimore, Md : 1950). 2011; 186(12):6822-6829.

52. Osaka E, Yang X, Shen JK, Yang P, Feng Y, Mankin HJ, Hornicek FJ and Duan Z. MicroRNA-1 (miR-1) inhibits chordoma cell migration and invasion by targeting slug. Journal of orthopaedic research : official publication of the Orthopaedic Research Society. 2014; 32(8):1075-1082.

53. Zhang L, Guo S, Schwab JH, Nielsen GP, Choy E, Ye $\mathrm{S}$, Zhang Z, Mankin H, Hornicek FJ and Duan Z. Tissue microarray immunohistochemical detection of brachyury is not a prognostic indicator in chordoma. PloS one. 2013; 8(9):e75851. 